\title{
Mechanical performance of novel cement-based composites prepared with nano-fibres, and hybrid nano- and micro- fibres
}

\author{
S. ALREKABI ${ }^{\mathrm{A}, \mathrm{B}}$, A.B.CundY ${ }^{\mathrm{C}^{*}}$, A. LAMPROPOULOS ${ }^{\mathrm{A}}$, RAYMOND L.D. WhitBY ${ }^{\mathrm{D}}$, I. SAVINA ${ }^{\mathrm{E}}$ \\ ${ }^{\text {A }}$ School of Environment and Technology, University of Brighton, UK \\ ${ }^{B}$ Dept. of Civil Engineering, University of Babylon, Babylon, Iraq \\ ${ }^{C}$ School of Ocean and Earth Science, University of Southampton, UK \\ ${ }^{D}$ School of Engineering, Nazarbayev University, Astana, Kazakhstan \\ ${ }^{E}$ School of Pharmacy and Biomolecular Sciences, University of Brighton, UK
}

\begin{abstract}
Use of hybrid fibre composites that exploit the synergistic effect of nano- and micro- additives can potentially lead to significant improvements in the toughness and mechanical properties of fibre reinforced cementitious materials. In this study, the mechanical properties of two types of novel cementitious composite (Carbon Nano-Fibre (CNF) Composites, and Hybrid-Fibre Composites) at various curing ages have been evaluated, along with their microstructure. Experimental results show a positive impact of nano-fibres on the mechanical performance of the cementitious composites: improvements of $40 \%$ in flexural strength, $45 \%$ in tensile strength, and $85 \%$ in toughness were observed when a low mass \% $(0.025 \%)$ of CNFs was combined with steel fibres. SEM observations revealed that reinforcement at the nanoscale prevented nano-crack development within the composites, with a greater amount of energy required to initiate and propagate cracks and cause material failure.
\end{abstract}

*Corresponding author, (023)80596179. Email: A.Cundy@soton.ac.uk (A.B.Cundy)

Keywords - Carbon fibres; hybrid composites; reinforced concretes; nanocomposites. 


\section{Introduction}

Cementitious materials are generally highly brittle with low tensile strength and strain capacity, and hence failure of cement based materials at relatively low load is a common multi-scale process which affects the long-term durability of structures [1,2]. Reinforcement of cementitious composites at micro-scales can significantly improve material toughness however by controlling crack propagation [3,4]. The most frequently used reinforcing fibres are organic fibres (such as polypropylene, nylon, and polyvinyl alcohol fibres), natural cellulose (such as hardwood and softwood pulps), and inorganic fibres (such as steel, glass and carbon) [5, 6]. Steel fibres, polypropylene (pp), and recently polyvinyl alcohol (PVA) fibres have attracted much attention due to the outstanding toughness and mechanical performance of composites reinforced with these materials [7-10].

Recent developments in fibre reinforced composites have also highlighted the positive effect of using hybrid systems of micro and macro fibres, or of applying different types of micro fibre [11, 12]. The benefits of applying hybrid fibres reflects the fact that concrete has a multiscale structure, consisting of micron- and sub-micron scale hydration products, millimetre scale sand and non-hydrated cement grains, and (if gravel is used as an aggregate) centimetre scale clasts. The addition of fibres of different sizes leads to an improvement in the properties of the composites at both micro- and macro-levels - at the micro-level the fibres act to inhibit the initiation and growth of cracks $[13,14]$. While use of one type/size of fibre can delay the propagation of microcracks, this does not stop their formation [15-17]. 
Recently, a number of attempts have been made to incorporate nanoscale fibres into cementitious composites, to provide reinforcement at the nano scale and to effectively bridge nano-cracks during loading and transferral of load [18-20]. Nanoscale fibres can delay the initiation of cracks at the nanoscale, and thus higher loads are required to form the crack, which improves the weak tensile strength of the cementitious matrix [17]. Most of the published studies to date focus on carbon nanofilaments (carbon nanotubes (CNTs) and carbon nanofibers (CNFs)) as reinforcing agents due to their remarkable mechanical properties such as high Young's modulus (which for CNTs is around $1 \mathrm{TPa}$ ), high tensile strength (ca. 50-200 GPa), and fracture strain as high as 280\% [19, 21]. Carbon nanofilaments can inhibit crack formation and delay the failure process: cracks in cementbased materials initiate from the nanoscale, and microfibers fail to stop crack initiation at this scale [22]. Yu et al. [5] have shown that the mechanical strength of cementitious composites could be significantly improved by mixing carbon-based nano additives into cement-based materials [23-29]. Campillo et al. [23] have investigated the enhancement effects of incorporated multiwall carbon nanotubes (MWCNTs) on the compressive strength of cement pastes, and showed that MWCNTs generated significant improvements in compressive strength. Li et al. [24, 25] observed a $25 \%$ increase in flexural strength and a $19 \%$ increase in compressive strength by using carboxylate group MWCNTs. Cwirzen et al. $[26,27]$ reported that the addition of MWCNTs at $0.045-0.15 \%$ of the cement weight led to a 50\% increase in compressive strength of cement paste specimens, while Yakovlev et al. [28] have showed that inclusion of CNTs (at $0.05 \%$ by mass) resulted in a $70 \%$ increase in compressive strength, from 0.18 MPa to 0.306 MPa. Abu Al-Rub et al. [29] investigated the flexural strength of cement specimens containing short $(0.2$ wt. \%) and long $(0.1$ wt. \%) 
MWCNTs, and noted increases of $26.9 \%$ and $65 \%$, respectively, compared with a plain cement sample at $28 \mathrm{~d}$ curing.

To date, however, there are no published studies on the use of a hybrid system of steel fibres and MWCNTs, and there is only one published study on the synergistic effect of micro steel fibres and CNFs to achieve superior tensile strength and fracture toughness. Ahmed et al.[15] examined the effect of a hybrid reinforcement system (via a combination of steel fibres and CNFs) on the engineering properties of ultrahigh performance concrete (UHPC). The results of a combination of $1.1 \%$ ( by mix volume) steel fibres and $0.04 \%$ CNFs were $50 \%, 240 \%, 2700 \%, 236 \%, 1200 \%$, and $5 \%$ improvements in the flexural strength, maximum deflection, energy absorption capacity, impact resistance, abrasion resistance, and compressive strength of (plain) UHPC, respectively. The combination of nano and microscale reinforcement was found to enhance the reinforcing efficiency at different scales, where the nano fibres can bridge the cement hydration production at the nanoscale while the micro fibres are more efficient in preventing the development of macro-cracks $[30,31]$. Ahmed et al.'s study is relatively limited in scope however, and investigates only one type of carbon nanofilament, despite the different physical and chemical properties of available CNFs. Therefore, here we examine the effect of MWCNTs, F-MWCNTs, and CNFs incorporation on the mechanical performance of cementitious composites, and their combination with steel fibres in a hybrid (nano-micro fibre) system. Results are presented from direct tensile strength, compressive strength and fracture toughness testing, and SEM analysis. 


\section{Experimental details}

\subsection{Materials}

Ordinary Portland Cement (OPC) meeting the requirements of British Standard BS EN 1971 and Elkem Microsilica Grade 940 were used as cementitious materials. Sand with a grain size of less than $0.5 \mathrm{~mm}$ was used as the fine aggregate. Polycarboxylate superplasticizer (SP) was used to achieve good workability. Hybrid reinforced materials were produced using micro steel fibres and various carbon nanotubes/fibres: i) conventional available multiwall carbon nanotubes (MWCNTs), ii) functionalised multiwall carbon nanotubes (FMWCNTs), and iii) carbon nanofibres (CNFs). MWCNTs and F-MWCNTs were purchased from Cheaptubes, Inc. (cat\# sku-030102, Brattleboro, VT, USA), and CNFs were purchase from Sigma Aldrich, UK. The nanotubes/fibres were used at a set percentage of $0.025 \%$ by cement weight, and micro steel fibres were used in a volume fraction of $2 \%$. The physical properties as provided by the suppliers are presented in Table 1 .

\subsection{Dispersion of nano suspensions and specimens preparation}

Nano suspensions were prepared using the nano additive at a ratio of $0.025 \%$ wt. by weight of cement, SP at $0.4 \%$ wt. of cement powder, and $1 / 4$ quantity of mixing water. The suspensions were sonicated using a tip ultrasonic probe (Sonic FB-705) set to deliver high intensity ultrasonic energy, which was set to $100 \%$ amplitude and operated in $20 \mathrm{~s}$ cycles over 5 minutes' duration, following [32]. 
After the preparation of the suspensions, four mixtures for each nano-fibre composite and hybrid- fibre composite were prepared, at mix proportions shown in Table 2. Nanocomposite mixtures were labelled as: $\mathrm{CT}, \mathrm{CTf}$, and $\mathrm{CF}$ to represent cementitious composites containing MWCNTs, F-MWCNTs, and CNFs, respectively. Mixtures of hybrid-fibre composite systems with steel fibres were labelled as: CT-SF; CTf-SF; and CF-SF, to represent cementitious composites containing a hybrid of steel fibres and MWCNTs, FMWCNTs, and CNFs respectively, as shown in Table 3.

All dry ingredients (cement, microsilica, and sand) were first mixed for 2 minutes in a high shear mixer (Zyklos Pan Mixer ZZ 75 HE), then water and SP were added (remaining quantity). Micro fibres (for hybrid-fibre mixtures) were gradually added and mixing continued for another 2 minutes. The suspension was then added and mixed for a further 4 minutes. The mixing procedure for the nano-fibre composites and hybrid-fibre composites is illustrated schematically in Fig.1 (a, b).

The prepared hybrid-fibre mixes were poured (following ASTM C192) [33] into wooden dog-bone shaped moulds, and plastic moulds for compressive and flexural tests, with dimensions (100x100x100) $\mathrm{mm}$ in accordance to BS EN12390-3: 2009 [34], and 100mmx $100 \mathrm{~mm} \times 500 \mathrm{~mm}$ in accordance to ASTM C1609/C1609M [35], respectively. The nanofibre composite mixes were poured into metal dog-bone shaped moulds, cubic moulds of 50mmx50mmx50mm in accordance with ASTM C109 [36], and prism bar moulds of 40mmx40mmx $160 \mathrm{~mm}$ in accordance to ASTM C293 [37]. The moulded composites were consolidated using a vibration table at high intensity. Following setting, samples were de- 
moulded and cured in water until testing. For comparison, control mixtures of cementitious paste, and composites with steel fibres, were also prepared and labelled as PC, PC-SF, respectively. To cast the control cementitious composite, SP was firstly dissolved in water. Then, sand, cement and silica fume were mixed uniformly in a concrete centrifugal blender for 2 minutes, after which the mixture of water and superplasticizer was poured in and stirred for 4 minutes. Then the steel fibres (for composite mixtures) were gradually added and mixed for a further 5 minutes.

\subsection{Testing specifications}

The compressive strengths of nano-fibre composite and hybrid-fibre composite specimens were examined 3, 28, and 90 days after casting. Three specimens were examined for each test under a constant compressive load rate of $0.75 \mathrm{kN} / \mathrm{s}[36,38]$, and $3 \mathrm{kN} / \mathrm{s}$ [34], respectively. Four-point bending tests were performed with the aim of characterising the ultimate flexural strengths, post-cracking behaviour, and fracture energy of the fibre composites [39]. For the flexural strength test: i) for nano-fibre composites, prisms were tested under centre-point loading with a displacement rate of $0.18 \mathrm{~mm} / \mathrm{min}$ and span of 120 mm using an Instron Testing Machine (Intron Model 8630), the deflection was measured using two linear variable differential transducers (LVDTs); ii) beams of 100x100x500mm were tested under four-point loading at a loading rate of $0.24 \mathrm{~mm} / \mathrm{min}$, LVDTs were fixed on both sides of the set-up to measure the vertical deformation at mid cross-section of the specimen, as shown in Fig.2(a). The flexural strength was calculated based on the average of results of three specimens, in accordance to ASTM C1081 and as per ASTM C1609[35]. 
Maximum flexural strength $(f)$ was calculated by substituting experimental test data into Eq. (1), and Eq (2) [23]:

$f=(\mathrm{P} \mathrm{L}) / \mathrm{bd} 2$

(Four-point loading test)

$f=(3 \mathrm{P} \mathrm{L}) / 2 \mathrm{bd} 2$

(Centre-Point Loading test)

Where;

$f$ : Flexural strength in MPa.

P: Load in N.

L: Span length in mm.

$\mathrm{b}$ and $\mathrm{d}=$ breadth and depth (in $\mathrm{mm}$ ) of the beam, respectively.

Due to the difficulties of accurately identifying the exact location of the first crack point on the load deflection curve in accordance to ASTM C1081, the load-deflection curves were analysed in accordance to JSCE-SF4 Japan Society of Civil Engineering, Standard for Flexural Strength and Flexural Toughness [40]. The Flexural toughness factor $\left(\mathrm{FT}_{\delta}\right)$ is calculated using Eq. 3 [41] (Fig. 2 (b) shows a typical diagram of the load- deflection relationship used to calculate the Flexural toughness factor $\left.\left(\mathrm{FT}_{\delta}\right)\right)$.

$\mathrm{FT}_{\delta}=(\operatorname{Tb} \delta \times l) /\left(\begin{array}{lllll}\delta & x & b & \times & h 2\end{array}\right)$ 
Where $\mathrm{FT}_{\delta}=$ Flexural toughness factor at a beam displacement of $\delta, \mathrm{T}_{\mathrm{b} \delta}=$ Area under the load-versus-deflection plot up to a deflection of $\delta, 1=$ Span length, and b width and $h=$ depth of the beam.

Dog bone-shaped specimens of the dimensions shown in Fig.3 were used to detect elongation occurring during the test, and to understand the behaviour of the composites under monotonic direct-tensile load. An Instron testing machine was used to perform tensile tests at a constant displacement rate of $0.18 \mathrm{~mm} / \mathrm{min}$, following the ASTM standard D638. Linear Variable Differential Transformers (LVDTs) were attached near the grips connected to the specimen. The average elongation was obtained from the two LVDTs placed on opposite sides of the specimen. The fracture surfaces of test specimens were examined using Scanning Electron Microscopy (SEM, via a Zeiss model LEO 1455VP field emission scanning electron microscope).

\section{Results and discussion}

\subsection{Compressive Strength}

Compressive strength test results for nano-fibre composites and hybrid-fibre composites specimens are shown in Fig 4. The improvement in the compressive strength of the mixtures containing different nano-fibres; i.e. MWCNTs, F-MWCNTs, and CNFs at 3, 28, and 90 days was approximately: 30\%, 35\%, 38\%; 28\%, 24\%, 32\%; and 11\%, 15\%, 20\%, compared to the control mix. These results are in good agreement with previous finding reported by $[2,24,29]$. This compressive strength gain can be attributed to the physical 
contribution of dispersed nano-fibres, wherein they act as a strengthening filler and nanoreinforcing agent (reinforcing the cement hydration products such as calcium silicate hydrates (C-S-H) and ettringite), thus contributing to an enhancement in the load bearing capacity of the cement matrix.

The increase in compressive strength of hybrid-fibre composites can be attributed to the action of nano and micro fibres simultaneously throughout the composite. Steel fibres play a major role in delaying the development of micro-cracks, and limiting the propagation of these micro-cracks, as well as providing a transverse confinement effect $[42,43]$. At the same time, carbon nano-fibres act as a filler and reinforcing agent resulting in densely packed reinforced microstructure. This combination therefore contributes to producing a denser composite reinforced from the nanoscale, which enables the applied load to be more evenly transferred between the matrix and the reinforcement fibres.

\subsection{Flexural behaviour}

Mean ultimate static flexural strengths of nano-fibre composites and hybrid-fibre composites, and their improvement relative to control specimens, after 3, 28, and 90 days curing are shown in Table 4. The maximum increase in flexural strength due to the addition of MWCNTs, F-MWCNTs, and CNFs compared to the flexural strength of PC specimens, was $9 \%, 17 \%$, and $24 \%$, and $7 \%, 8 \%, 22 \%$ and $8 \%, 7 \%, 32 \%$ after $3,28,90$ days respectively. The increase in flexural strength observed agrees with previous studies [19, 29, 44-46], although here lower percentages of nano-fibres ( $0.025 \mathrm{wt} . \%$ of cement) are used, and the dispersion method differs [32]. The significant strength gains of the CNF-composite 
can be attributed to i) fibre length, which is much longer compared to nanotubes (about four times longer), and ii) their deformed geometry (conical shape) allowing for a stronger bond with the surrounding matrix, and therefore increasing the overall mechanical performance of CNFs composites [45].

The strength enhancement given by hybrid-fibre composites is obviously higher than with the cementitious composites containing only nano-fibres. The addition of MWCNTs, FMWCNTs, and CNFs combined with micro steel fibres led to an improvement in flexural strength which varied from $17 \%, 47 \%$, and $40 \%$, and $12 \%, 25 \%, 23 \%$, and $10 \%, 32 \%, 29$ $\%$ after 3,28, 90 days respectively. This can be attributed to the action of nano-fibres bridging the cement hydration products (leading to a higher tensile strength of the composite), while the longer steel fibres arrest the propagation of microcracks and substantially improve the toughness and ductility of the composite $[12,47]$.

Average load-deflection curves of hybrid-fibre composites after 3 and 28 days are shown in Figs.5 and Figs.6 respectively. Based on the JSCE analysis method, toughness is defined as the area under the load deflection curve up to a deflection of 1/150th of the span length, Fig 2(b). The results of the toughness factor up to $3 \mathrm{~mm}$ of deflection are presented in Table 5.

The addition of CNTs, CNFs, and F-CNTs led to a significant improvement in absorbed energy, and relative to the control specimens improvements of $23 \%, 66 \%, 86 \%$, and $37 \%$, $60 \%, 58 \%$ were obtained after 3 and 27 days, respectively. Nano-fibres seem to inhibit 
nano-cracks and restrict their growth within the composites, and improve their ability to carry greater loads, as there is a need for a greater amount of energy to produce the cracks.

\subsection{Flexural Stiffness}

The load-deflection response of the hybrid-fibre composites at various curing ages was also analysed in terms of flexural stiffness. The effective flexural stiffness was significantly improved when nano-fibres were added to the steel fibre composites, indicating that the nano-fibres delayed the first yield and the deflection at ultimate load. Compared to the measured stiffness of specimens with only steel fibres, the effective flexural stiffness of hybrid-fibre composites containing MWCNTs, F- MWCNTs, and CNFs, was higher by $32 \%, 36 \%$, and $41 \%$; and by $35 \%, 30 \%$, and $36 \%$ after 3 and 28 days respectively.

These results indicate that with the addition of nanoscale fibres, the composite specimens show higher resistance against bending deformation. This is due to the reinforcing efficiency of nano-fibres, which can lead to absorption of greater amounts of energy by inhibiting cracking at nano scales, and thereby increasing the energy needed to propagate the cracks.

\subsection{Direct Tensile Test (Dog-bone Test)}

Direct tensile strength results for nano-fibre composites and hybrid-fibre composites after 3, 28, and 90 days of curing are shown in Fig.8. The results indicate that the addition of nanoscale fibres significantly increased the tensile strength of the composites. For nano-fibre composites, addition of MWCNTs, F-MWCNTs, and CNFs increased the tensile strength by 
$37 \%, 18 \%$, and $18 \% ; 29 \%, 16 \%$, and $19 \%$; and $42 \%, 19 \%, 16 \%$, after 3,28 , and 90 days, respectively. Moreover, in hybrid-fibre composites, these additions increased the tensile strength by $46 \%, 41 \%$, and $34 \% ; 47 \%, 49 \%$, and $52 \%$; and $45 \%, 45 \%, 43 \%$, after 3,28 , and 90 days, respectively, improvements which confirmed the positive synergistic effects between the nano-and-micro fibres.

Overall, higher improvements resulted from the use of F-MWCNTs and CNFs. For the former, this may be a function of the carboxyl groups on the tubes walls which leads to a better dispersion level, and improves the bond between the nanotubes and the surrounding matrix [24]. The geometry of CNFs compared to MWCNTs (i.e. their outer surfaces are conically shaped and angled with respect to the longitudinal fibre axis) [45] can lead to improved bonding with the matrix, and bridging of cracks, improving the load carrying capacity [29]. In addition to these reasons, the strength gain with the hybrid systems can also be attributed to the reinforcement effect over different scales (i.e. the positive synergistic effect between the nano and micro fibres). The distribution of nano-fibres throughout the microstructure densifies the material and reinforces the hydration products, and acts as a nano strengthening agent, better distributing stresses at the micro scale.

\subsection{Composite Microstructures}

Scanning electron microscopy (SEM) was performed on the fracture surface of dog-bone specimens (small size specimens of $25.4 \times 20 \times 7 \mathrm{~mm}$ ) before and after tensile testing to examine (a) composite microstructure, and (b) failure mechanisms. The uniform dispersion 
of fibres (both nano and/or micro) is essential to obtain composites with enhanced mechanical properties. Figs.9 (a, b) show high-magnification SEM images of MWCNTsand CNFs- containing specimens, indicating that the nanotubes/fibres are adequately dispersed (mostly nano-fibres can be identified on the examined regions), and appear embedded into the hydration products, arresting the nanostructure. These observations are in agreement with previous studies [26, 29, 45, 48], which revealed that the crack bridging function of carbon nano-fibres incorporated into a cementitious matrix is significantly affected by the dispersion status, and strong surface interaction with the surrounding matrix. Figs.10 (a) shows an SEM image at low magnification of the specimens with 2\% mass fraction of steel fibres, indicating that steel fibres were distributed homogenously in the composite. Fig10 (b) shows the steel fibre-matrix interface, and the micro cracks formed during the test, highlighting that although the microfibres can delay the propagation of microcracks, they do not arrest cracks with a smaller scale and stop their initiation. Due to the large difference between the diameter of the micro and nano-fibres, it is not possible using SEM to show the simultaneous (synergistic) reinforcement effects of micro-scale steel fibres and nano-scale fibres.

The crack-reinforcing mechanisms of CNTs and CNFs in the composite can be clearly observed after the formation of the first crack. Fig.11 (a) and (b) respectively show the formed crack, and the carbon nanotubes along both sides of the crack. Nanotubes were ruptured and/or pulled-out of the matrix after the peak stress was reached, indicating the contribution of nanotubes in enhancing the load bearing capacity and crack-resisting 
characteristics. Fig.11 (c) shows the effect of nanotubes in reinforcing the matrix hydration products.

Similar to SEM images of the CNTs, Fig.12 shows the reinforcing mechanism of the carbon nanofibres. The longer nanofibers (which are around four times longer than nanotubes), act to i) provide a larger contact area with the surrounding matrix which may increase their ability to withstand pulling-out and/or rupture forces, thus promoting higher load carrying capacity, ii) increase the ability of nanofibres to prevent crack propagation from nano to micron then macro scale.

\subsection{Comparison between Nano-Fibres Composites and Hybrid-Fibre Composites}

Strength improvement (relative to the strength of control specimens) of nano-fibre composites specimens and hybrid-fibre composites specimens are shown in Fig.13 and

Fig.14. Generally, the addition of fibres in the nano scale significantly improved the mechanical strength of a composite, moreover the impact of CNF was higher compared to MWCNTs, and F-MWCNTs. The addition of CNFs was found to offer a significant enhancement in mechanical properties to the cementitious composites, mainly increased tensile strength (by 42\%, 19\%, and $16 \%$ ), and increased compressive strength (by $38 \%$, $32 \%$, and 20\%), after 3,28 , and 90 days respectively, in addition to distinct improvements in cracking control. Different behaviour was observed when the nano-fibres were combined with $2 \%$ micro steel fibres in the hybrid-fibre composites. While no distinct improvement was observed in the compressive strength, a significant enhancement in the tensile strength was obtained, with all type of nano-fibres. 
Overall, the reinforcing efficiency of the CNFs in the cementitious matrix was shown to depend on their geometry and morphology, and the adsorbed layer of SP. The SP layer on the outer surface of the nanofibres acts as a linking site with the surrounding matrix which can further improve the mechanical performance (Fig 15a). Compared to the other type of nano-fibres tested in this study, the rougher surface of CNFs (consisting of conically shaped graphite planes) combined with their greater length (around four times longer than MWCNTs) acts to enhance the bond area with the matrix. Thus a composite with a higher load transfer efficiency between the fibres and the matrix will be obtained. TEM images (Fig.15 a and b) confirm the morphology of the used nanofibres and the presence of a SP layer on their outer surfaces.

\subsection{Discussion}

Although several studies have investigated the enhancement of the mechanical properties of cementitious composites which accompanies the addition of nanotubes/fibres, no consensus has yet been reported on their beneficial effects [2, 19, 24, 25, 29, 30, 49]. Observed differences in the impact of nanotubes/fibres incorporation are reported to depend strongly on various parameters, such as the type of nano fibres used, their concentration, and the dispersion method, as well as the properties of the cementitious matrix. In this study a very low percentage of MWCNTs, F-MWCNTs, and CNFs, (0.025\% by cement weight) dispersed following previously outlined methods [32] were found to significantly improve the compressive, direct tensile and flexural strengths of nano-fibre and hybrid-fibre composites. 
The improvement in properties of the nano-fibre composites can be attributed to i) the nanofibre bridging mechanisms, which involve reinforcing the cement hydration products, and ii) a packing effect, with the extremely small particles acting as fillers, filling the voids (spaces) (at nano-and/or micro level) that exist within and around the ettringite products within the hydrated cement paste.

In addition to these reasons another important factor may explain the positive synergistic effect between nano- and-micro fibres in hybrid-fibre composites. This relates to the prevention of multiscale crack propagation, whereby nano and micro fibres act to prevent the initiation of nanocracks and microcracks respectively (with nano-fibres bridging the hydration products, while the micro fibres arrest the hydration products at larger scale), and a multiscale reinforcing effect, whereby reinforcement with nano fibres improves the properties of the unreinforced material between the microfibres, and thus increases the possibility of even stress distribution throughout the matrix, and improves transfer of load from the matrix to the reinforcing fibres.

\section{Conclusion}

The improvement in the mechanical performance of cementitious composites with the addition of nano-fibres can be attributed in part to the reinforcing capability of these fibres, which act to delay the nano and then micro-crack propagation. In addition, nano-fibres act as a filler in the interstitial spaces of cement hydration products, therefore the composites become denser and better able to withstand the applied stresses. Nano-fibres within hybrid- 
fibre composites contribute to a multiscale reinforcing efficiency, acting to reinforce cement hydrations products in the nano scale while the longer fibres (i.e. steel fibres) arrest the microstructures and prevent the propagation of microcracks. Moreover, and for the same reason, the hybrid system was found to significantly delay the first crack formation, as the multi-scale reinforced structure increased the energy needed to initiate the cracks, and therefore contributed to obtaining a new tougher composite. Although all of the examined nano-fibres exhibited a positive effect in the examined composites, CNFs were found to significantly improve the mechanical performance. This can be attributed to the higher aspect ratio of CNFs compared to MWCNTs, which can lead to a better capacity for bridging cracks and improving the load carrying capacity. SEM investigation supported the improved reinforcing efficiency of CNFs over MWCNTs, their higher aspect ratio enhancing their ability to withstand pulling-out and/or rupture forces.

\section{Acknowledgment}

The lead author would like to thank the Iraqi Ministry of Higher Education and Scientific Research, Iraqi Culture attaché in London, and Babylon University in Iraq for award of a Doctoral scholarship

\section{References}

1. Li, V.C., H-C. Wu, Conditions for Pseudo Strain-Hardening in Fiber Reinforced Brittle Matrix Composites. Applied Mechanics Reviews, 1992. 45: 390-398. 
2. Xu, S., J. Liu, Q. Li, Mechanical properties and microstructure of multi-walled carbon nanotubereinforced cement paste. Construction and Building Materials, 2015. 76: 16-23.

3. Yoo, D-Y., H-O.Shin., J-M.Yang, Y-S. Yoon, Material and bond properties of ultra high performance fiber reinforced concrete with micro steel fibers. Composites Part B: Engineering, 2014. 58: 122-133.

4. Qian, C.X., P.Stroeven, Development of hybrid polypropylene-steel fibre-reinforced concrete. Cement and Concrete Research, 2000. 30: 63-69.

5. Yu Hu, D.L., P.Li, Q.Li, G.Sun, Fracture toughness enhancement of cement paste with multi-walled carbon nanotubes. Construction and Building Materials, 2014. 70: 332-338.

6. Musso, S., et al., Influence of carbon nanotubes structure on the mechanical behavior of cement composites. Composites Science and Technology, 2009. 69: 1985-1990.

7. Islam, S.M., R.R. Hussain, M.A.Z. Morshed, Fiber-reinforced concrete incorporating locally available natural fibers in normal-and high-strength concrete and a performance analysis with steel fiber-reinforced composite concrete. Journal of Composite Materials, 2012. 46: 111-122.

8. Şahin, Y., F. Köksal, The influences of matrix and steel fibre tensile strengths on the fracture energy of high-strength concrete. Construction and Building Materials, 2011. 25: 1801-1806.

9. Centonze, G., M. Leone, M.A. Aiello, Steel fibers from waste tires as reinforcement in concrete: A mechanical characterization. Construction and Building Materials, 2012. 36: 46-57.

10. Pan, Z., et al., Study on mechanical properties of cost-effective polyvinyl alcohol engineered cementitious composites (PVA-ECC). Construction and Building Materials, 2015. 78: 397-404.

11. Banthia N., V. Bindiganavile, Performance Synergy in Hybrid Fiber Reinforced Concrete Under Impact. Journal of Frontiers in Construction Engineering, 2013. 2: 75-82.

12. Yusof, M.A., N.M.Nor, A.Ismail, N-C. Peng, R.M. Sohaimi, M.A.Yahya, Performance of Hybrid Steel Fibers Reinforced Concrete Subjected to Air Blast Loading Advances in Materials Science and Engineering, 2013. http://dx.doi.org/10.1155/2013/420136.

13. Banthia, N., M.Sappakittipakorn, Toughness enhancement in steel fiber reinforced concrete through fiber hybridization. Cement and Concrete Research, 2007. 37: 1366-1372. 
14. Shah S.P.,P.N. Balaguru, Fiber-Reinforced Cement Composites, McGraw-Hill Inc., New York, 1992, pp 530 .

15. Ahmed Sbia, L., et al., Enhancement of Ultrahigh Performance Concrete Material Properties with Carbon Nanofiber. Advances in Civil Engineering, 2014: http://dx.doi.org/10.1155/2014/854729.

16. Metaxa, Z., M. Konsta-Gdoutos, S. Shah, Carbon Nanofiber-Reinforced Cement-Based Materials. Transportation Research Record: Journal of the Transportation Research Board, 2010. 2142: 114118.

17. Han, B., X. Yu, J. Ou, Multifunctional and Smart Carbon Nanotube Reinforced Cement-Based Materials, in Nanotechnology in Civil Infrastructure, K. Gopalakrishnan, et al., Eds. 2011, Springer Berlin Heidelberg. p. 1-47.

18. Hanus, M.J. and A.T. Harris, Nanotechnology innovations for the construction industry. Progress in Materials Science, 2013. 58: 1056-1102.

19. Siddique, R. and A. Mehta, Effect of carbon nanotubes on properties of cement mortars.

Construction and Building Materials, 2014. 50: 116-129.

20. Ashour, A.I., Aspect Ratio Effect of Functionalized/Non-Functionalized Multiwalled Carbon Nanotubes on the Mechanical Properties of Cementitious Materials. Master's thesis, Texas A\&M University. Available electronically from http : //hdl .handle .net /1969.1/ETD -TAMU -2011 -08 10197. 2011.

21. Stynoski, P., P. Mondal, C. Marsh, Effects of silica additives on fracture properties of carbon nanotube and carbon fiber reinforced Portland cement mortar. Cement and Concrete Composites, 2015. 55: 232-240.

22. Díez-Pascual, A.M., et al., Nanoindentation in polymer nanocomposites. Progress in Materials Science, 2015. 67: 1-94.

23. Campillo I, D.J., Porro A. High-performance nanostructured materials for construction. in Proceedings of 1st international symposium on nanotechnology in construction. 2004. Cambridge (England).

24. Li, G.Y., P-M.Wang, X.Zhao, Mechanical behavior and microstructure of cement composites incorporating surface-treated multi-walled carbon nanotubes. Carbon, 2005. 43: 1239-1245. 
25. Li, G.Y., P-M. Wang, X. Zhao, Pressure-sensitive properties and microstructure of carbon nanotube reinforced cement composites. Cement and Concrete Composites, 2007. 29: 377-382.

26. Cwirzen, A., et al., SEM/AFM studies of cementitious binder modified by MWCNT and nano-sized Fe needles. Materials Characterization, 2009. 60: 735-740.

27. Cwirzen, A., K. Habermehl-Cwirzen, V. Penttala, Surface decoration of carbon nanotubes and mechanical properties of cement/carbon nanotube composites. Advances in Cement Research, 2008. 20: $65-73$.

28. Yakovlev, G., J.Kerienè, A.Gailius, I.Girnienè, Cement based foam concrete reinforced by carbon nanotubes. Materials Science [Medžiagotyra], 2006. 12: 147-151.

29. Abu Al-Rub, R.K., A.I. Ashour, B.M. Tyson, On the aspect ratio effect of multi-walled carbon nanotube reinforcements on the mechanical properties of cementitious nanocomposites.

Construction and Building Materials, 2012. 35: 647-655.

30. Konsta-Gdoutos, M.S., Z.S. Metaxa, S.P. Shah, Multi-scale mechanical and fracture characteristics and early-age strain capacity of high performance carbon nanotube/cement nanocomposites. Cement and Concrete Composites, 2010. 32: 110-115.

31. Kawashima, S., et al., Modification of cement-based materials with nanoparticles. Cement and Concrete Composites, 2013. 36: 8-15.

32. Alrekabi S., A.B.Cundy, A. Lampropoulos, I. Savina, Experimental Investigation on the Effect of Ultrasonication on Dispersion and Mechanical Performance of Multi-Wall Carbon NanotubeCement Mortar Composites. International Journal of Civil, Environmental, Structural, Construction and Architectural Engineering, 2016. 10: 267-274.

33. C192M-13a, A.C., Standard Practice for Making and Curing Concrete Test Specimens in the Laboratory, ASTM International, West Conshohocken, PA, 2013, www.astm.org.

34. BS EN 12390-3:2009 Testing hardened concrete. Compressive strength of test specimens. 2009.

35. C1609M-12, A.C., Standard Test Method for Flexural Performance of Fiber-Reinforced Concrete (Using Beam With Third-Point Loading), ASTM International, West Conshohocken, PA, 2012, www.astm.org. 
36. C109M-16a, A.C., Standard Test Method for Compressive Strength of Hydraulic Cement Mortars (Using 2-in. or [50-mm] Cube Specimens), . ASTM International, West Conshohocken, PA, 2016, WWW.astm.org.

37. C293M-16, A.C., Standard Test Method for Flexural Strength of Concrete (Using Simple Beam With Center-Point Loading), ASTM International, West Conshohocken, PA, 2016, www.astm.org.

38. Noorvand, H., et al., Incorporation of nano TiO2 in black rice husk ash mortars. Construction and Building Materials, 2013. 47: 1350-1361.

39. Baughman R.H., A.A.Zakhidov, W.A.de Heer, Carbon nanotubes - the route toward applications. Science. 2002. 297: 787-792.

40. JSCE-SF4 Standard for Flexural Strength and Flexural Toughness, Method of Tests for Steel fiber Reinforced Concrete, Concrete Library of JSCE, No. 3, June 1984, Japan Concrete Institute (JCI). pp. 58-66.

41. Banthia M., J-F., Trottier, Test Methods for Flexural Toughness Characterization of Fiber Reinforced Concrete. ACI Materials Journal, 1995. 1(92): 48-57.

42. Lee S-C., J-H. Oh, J-Y. Cho, Compressive Behavior of Fiber-Reinforced Concrete with End-Hooked Steel Fibers. Materials, 2015. 8: 1442-1458.

43. Jodeiri A.H., R.J.Quitalig, Effect of Wire and FS7-II Steel Wire Fibre on Flexural Capacity of Reinforced Concrete Beam. Journal of Civil Engineering Research, 2012. 6: 100-107.

44. Sobolkina, A., et al., Dispersion of carbon nanotubes and its influence on the mechanical properties of the cement matrix. Cement and Concrete Composites, 2012. 34: 1104-1113.

45. Metaxa, Z.S., M.S. Konsta-Gdoutos, S.P. Shah, Carbon nanofiber cementitious composites: Effect of debulking procedure on dispersion and reinforcing efficiency. Cement and Concrete Composites, 2013. 36: 25-32.

46. Shah, S.P., M.S. Konsta-Gdoutos, Z.S.Metaxa, Exploration of fracture characteristics, nanoscale properties and nanostructure of cementitious matrices with carbon nanotubes and carbon nanofibers. In Fracture Mechanics of Concrete and Concrete Structures -Recent Advances in Fracture Mechanics of Concrete - B. H. Oh, et al.(eds). 2010. Korea Concrete Institute, Seoul. 
47. Mohammadi, Y., S.P. Singh, S.K. Kaushik, Properties of steel fibrous concrete containing mixed fibres in fresh and hardened state. Construction and Building Materials, 2008. 22: 956-965.

48. Singh, A.P., et al., Multiwalled carbon nanotube/cement composites with exceptional electromagnetic interference shielding properties. Carbon, 2013. 56: 86-96.

49. Metaxa, Z.S., et al., Highly concentrated carbon nanotube admixture for nano-fiber reinforced cementitious materials. Cement and Concrete Composites, 2012. 34: 612-617. 
Table 1 Physical Properties of Nano-fibres and micro fibres.

\begin{tabular}{lllllll}
\hline Type & Diameter & Length & $\begin{array}{l}\text { Purity }(\% \\
\text { Carbon by } \\
\text { mass })\end{array}$ & $\begin{array}{l}\text { Modulus } \\
\mathrm{GPa}\end{array}$ & $\begin{array}{l}\text { Strength } \\
\mathrm{GPa}\end{array}$ & $\begin{array}{l}\text { Bulk } \\
\text { Density } \\
\left(\mathrm{g} / \mathrm{cm}^{3}\right)\end{array}$ \\
\hline CNTs & $\begin{array}{l}8-15 \mathrm{~nm} \\
\text { (outer } \\
\text { diameter })\end{array}$ & $(10-50) \mu \mathrm{m}$ & 95 & 1000 & $50-200$ & 1.95 \\
F- & $\begin{array}{l}8-15 \mathrm{~nm} \\
\text { (outer }\end{array}$ & $(10-50) \mu \mathrm{m}$ & 95 & 1000 & $50-200$ & 1.95 \\
CNTs & & & & & \\
CNFs & $\begin{array}{l}\text { diameter) } \\
100 \mathrm{~nm}\end{array}$ & $(20-200) \mu \mathrm{m}$ & - & 600 & 12 & 1.90 \\
Steel & $0.22 \mathrm{~mm}$ & $12 \mathrm{~mm}$ & - & 206 & 1 & 7.8 \\
Fibres & & & & & & \\
\hline
\end{tabular}

Table 2 Mix proportions

\begin{tabular}{|c|c|c|c|c|c|c|c|c|}
\hline Mixture type & $\begin{array}{l}\text { Water } \\
\text { to } \\
\text { binder } \\
\text { ration }\end{array}$ & $\begin{array}{l}\text { Water } \\
\mathrm{Kg} / \mathrm{m}^{3}\end{array}$ & $\begin{array}{l}\text { Cement } \\
\mathrm{Kg} / \mathrm{m}^{3}\end{array}$ & $\begin{array}{l}\text { Micro } \\
\text { Silica } \\
\mathrm{Kg} / \mathrm{m}^{3}\end{array}$ & $\begin{array}{l}\text { Silica } \\
\text { sand } \\
\mathrm{Kg} / \mathrm{m}^{3}\end{array}$ & $\begin{array}{l}\text { Super- } \\
\text { plasticiser } \\
\mathrm{Kg} / \mathrm{m}^{3}\end{array}$ & $\begin{array}{l}\text { Micro } \\
\text { steel } \\
\text { fibres } \\
\mathrm{Kg} / \mathrm{m}^{3}\end{array}$ & $\begin{array}{l}\text { Nano fibres } \\
\text { CNTs/CNFs } \\
\mathrm{Kg} / \mathrm{m}^{3}\end{array}$ \\
\hline $\begin{array}{l}\text { Nano-fibre } \\
\text { composites }\end{array}$ & 0.35 & 260 & 700 & 70 & 1050 & 2.8 & - & 0.175 \\
\hline $\begin{array}{l}\text { Hybrid-fibre } \\
\text { Composite }\end{array}$ & 0.35 & 260 & 700 & 70 & 1050 & 2.8 & 160 & - \\
\hline
\end{tabular}


Table 3 Addition proportions of nano and micro fibres in tested composites

\begin{tabular}{llllll}
\hline Mixture & MWCNTs & F-MWCNTs & CNFs & Steel & PVA \\
ID & $\%$ & $\%$ & $\%$ & Fibres & $\%$ \\
\hline PC & 0 & 0 & 0 & 0 & 0 \\
CT & 0.025 & 0 & 0 & 0 & 0 \\
CTf & 0 & 0.025 & 0 & 0 & 0 \\
CF & 0 & 0 & 0.025 & 0 & 0 \\
PC-SF & 0 & 0 & 0 & 2 & 0 \\
CT-SF & 0.025 & 0 & 0 & 2 & 0 \\
CTf-SF & & 0.025 & 0 & 2 & 0 \\
CF-SF & 0 & 0 & 0.025 & 2 & 0 \\
\hline
\end{tabular}

Table 4 Flexural strength of nano-fibre composites, and hybrid systems containing three different types of carbon-based nano-fibres, (MWCNTs, F-MWCNTs, and CNFs). \% increase shows the improvement resulting from the addition of nano-fibres relative to the control mix.

\begin{tabular}{|c|c|c|c|c|c|c|c|c|c|}
\hline \multirow{2}{*}{$\begin{array}{l}\text { Specimens } \\
\text { designation }\end{array}$} & & \multicolumn{2}{|c|}{$\begin{array}{l}\% \text { Fibre } \\
\text { Volume }\end{array}$} & \multicolumn{2}{|c|}{$\begin{array}{l}\text { Flexural Strength } \\
\text { (3day) }\end{array}$} & \multicolumn{2}{|c|}{$\begin{array}{l}\text { Flexural Strength } \\
\text { (28day) }\end{array}$} & \multicolumn{2}{|c|}{$\begin{array}{l}\text { Flexural Strength } \\
\text { (90day) }\end{array}$} \\
\hline & & $\begin{array}{l}\text { micro } \\
\text { Fibres }\end{array}$ & $\begin{array}{l}\text { Nano } \\
\text { fibres }\end{array}$ & $\begin{array}{l}\text { Mean } \\
\text { (MPa) }\end{array}$ & $\begin{array}{l}\% \\
\text { Increase }\end{array}$ & $\begin{array}{l}\text { Mean } \\
(\mathrm{MPa})\end{array}$ & $\begin{array}{c}\% \\
\text { Increase }\end{array}$ & $\begin{array}{l}\text { Mean } \\
(\mathrm{MPa})\end{array}$ & $\begin{array}{c}\% \\
\text { Increase }\end{array}$ \\
\hline \multirow{4}{*}{$\begin{array}{l}\text { nano-fibre } \\
\text { composites }\end{array}$} & $\mathrm{PC}$ & 0.00 & 0.00 & 3.4 & 0.0 & 6.5 & 0.0 & 6.6 & 0.0 \\
\hline & $\mathrm{CT}$ & 0.00 & 0.025 & 3.7 & 9.0 & 6.9 & 6.9 & 7.2 & 7.9 \\
\hline & CTf & 0.00 & 0.025 & 4.0 & 17.4 & 6.9 & 7.5 & 7.1 & 6.6 \\
\hline & $\mathrm{CF}$ & 0.00 & 0.025 & 4.2 & 23.5 & 8.0 & 24.3 & 8.7 & 31.5 \\
\hline \multirow{4}{*}{$\begin{array}{l}\text { Hybrid-fibre } \\
\text { Composites }\end{array}$} & PC-SF & 2.00 & 0.000 & 7.8 & 0.0 & 10.8 & 0.0 & 11.0 & 0.0 \\
\hline & CT-SF & 2.00 & 0.025 & 9.2 & 16.8 & 12.0 & 11.5 & 12.2 & 10.2 \\
\hline & CTf-SF & 2.00 & 0.025 & 11.5 & 46.8 & 13.4 & 24.8 & 14.6 & 31.8 \\
\hline & CF-SF & 2.00 & 0.025 & 11.0 & 40.0 & 13.2 & 22.6 & 14.2 & 28.6 \\
\hline
\end{tabular}


Table 5 Flexural toughness factor values of hybrid fibre composites after 3 and 28 days, containing three different types of carbon based nano-fibres, (MWCNTs, F-MWCNTs, and CNFs). \% increase shows the improvement resulting from the addition of nano-fibres relative to the control mix

\begin{tabular}{|c|c|c|c|c|c|c|c|}
\hline \multirow{2}{*}{$\begin{array}{l}\text { Specimens } \\
\text { designation }\end{array}$} & & \multicolumn{2}{|c|}{$\begin{array}{l}\% \text { Fibre } \\
\text { Volume }\end{array}$} & \multicolumn{2}{|c|}{$\begin{array}{l}\text { Flexural } \\
\text { toughness } \\
\text { factor (FT) } \\
\text { (3day) }\end{array}$} & \multicolumn{2}{|c|}{$\begin{array}{l}\text { Flexural toughness } \\
\text { factor }(\mathrm{FT}) \\
\text { (28day) }\end{array}$} \\
\hline & & $\begin{array}{l}\text { micro } \\
\text { Fibres }\end{array}$ & $\begin{array}{l}\text { Nano } \\
\text { fibres }\end{array}$ & $\begin{array}{l}\text { Mean } \\
(\mathrm{MPa})\end{array}$ & $\begin{array}{c}\% \\
\text { Increase }\end{array}$ & $\begin{array}{l}\text { Mean } \\
(\mathrm{MPa})\end{array}$ & $\begin{array}{c}\% \\
\text { Increase }\end{array}$ \\
\hline \multirow{4}{*}{$\begin{array}{l}\text { Hybrid } \\
\text { Fibre } \\
\text { Composites }\end{array}$} & PC-SF & 2.00 & 0.000 & 5.5 & 0.0 & 6.4 & 0.0 \\
\hline & CT-SF & 2.00 & 0.025 & 6.7 & 23.3 & 8.8 & 36.6 \\
\hline & CTf-SF & 2.00 & 0.025 & 9.1 & 66.2 & 10.3 & 59.9 \\
\hline & CF-SF & 2.00 & 0.025 & 10.1 & 85.8 & 10.1 & 57.5 \\
\hline
\end{tabular}


a)

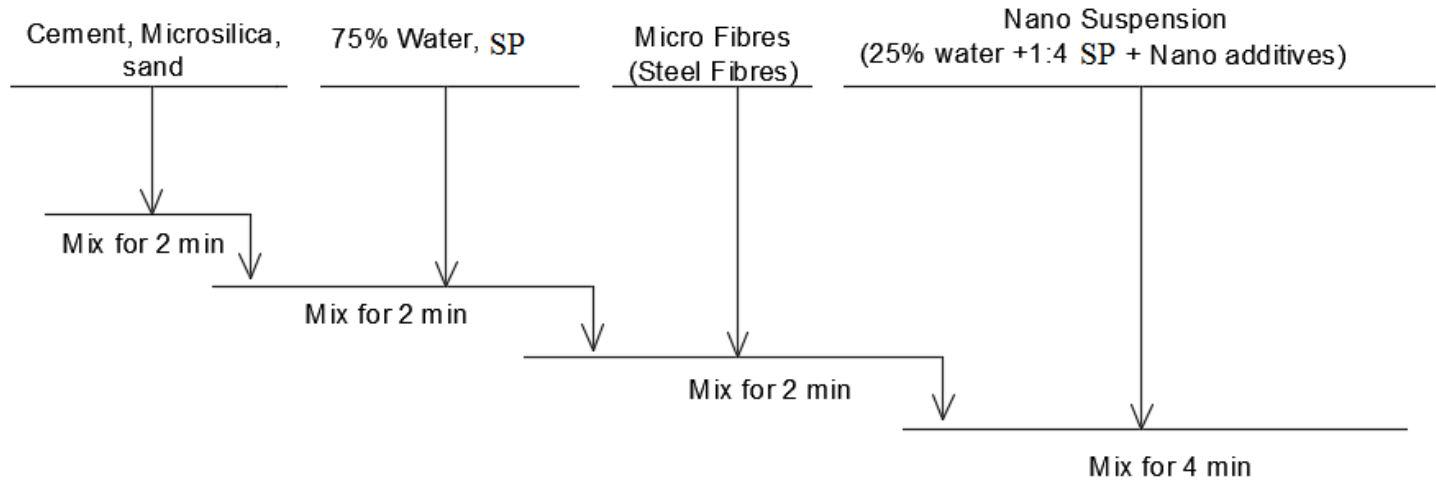

b)
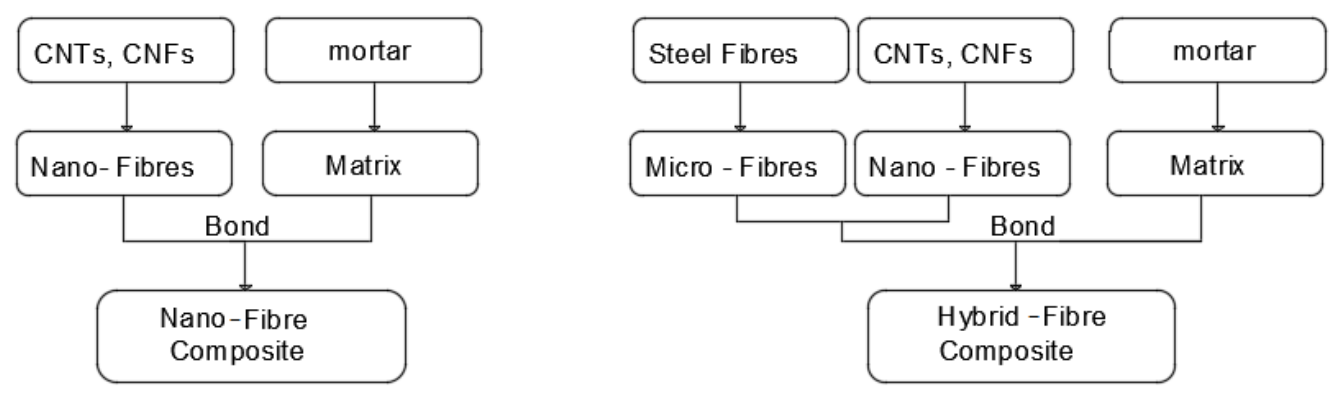

Fig. 1 a) Schematic mixing procedure for fresh mixtures; b) Ingredients of Nano-Fibre Composites and Hybrid-Fibre Composites

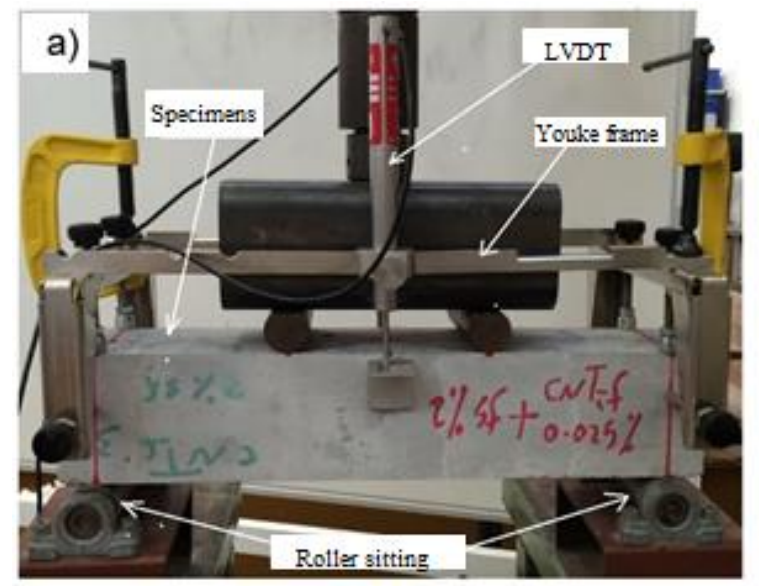

b)

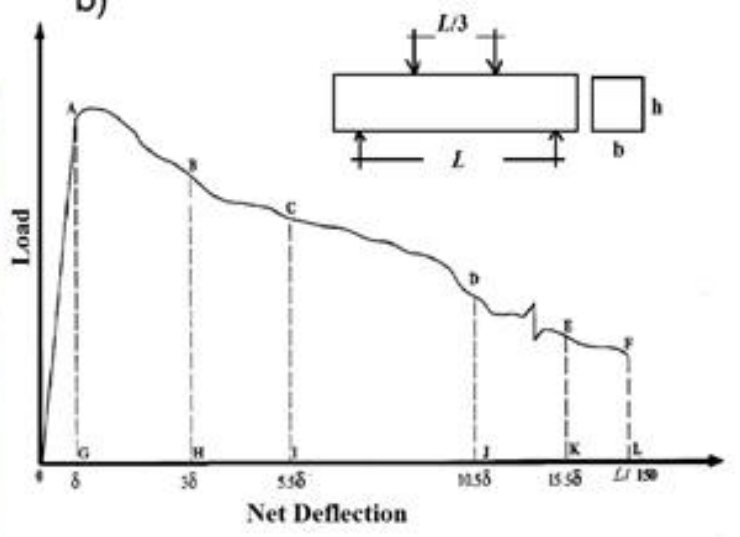

Fig. 2 a) Set up of flexural strength test under four point load, b) JSCE SF-4 technique of fibre-reinforced toughness characterization. 

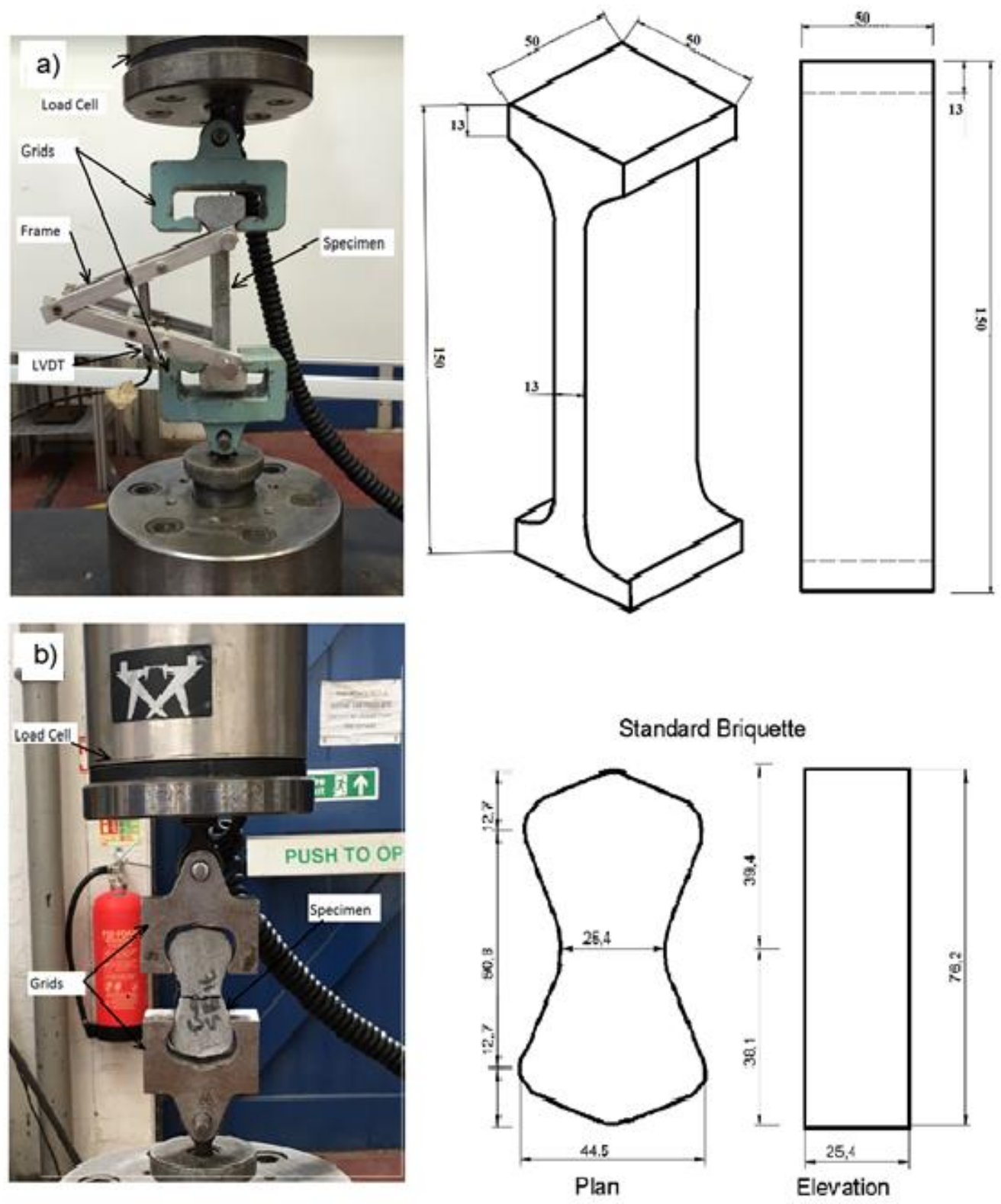

Fig. 3 a) Set up of direct tensile strength test using a) dog-bone shaped specimens for hybrid fibre composites direct tensile tests, and b) Standard Briquette used for nanofibre composites direct tensile tests (all dimensions in $\mathrm{mm}$ ) 


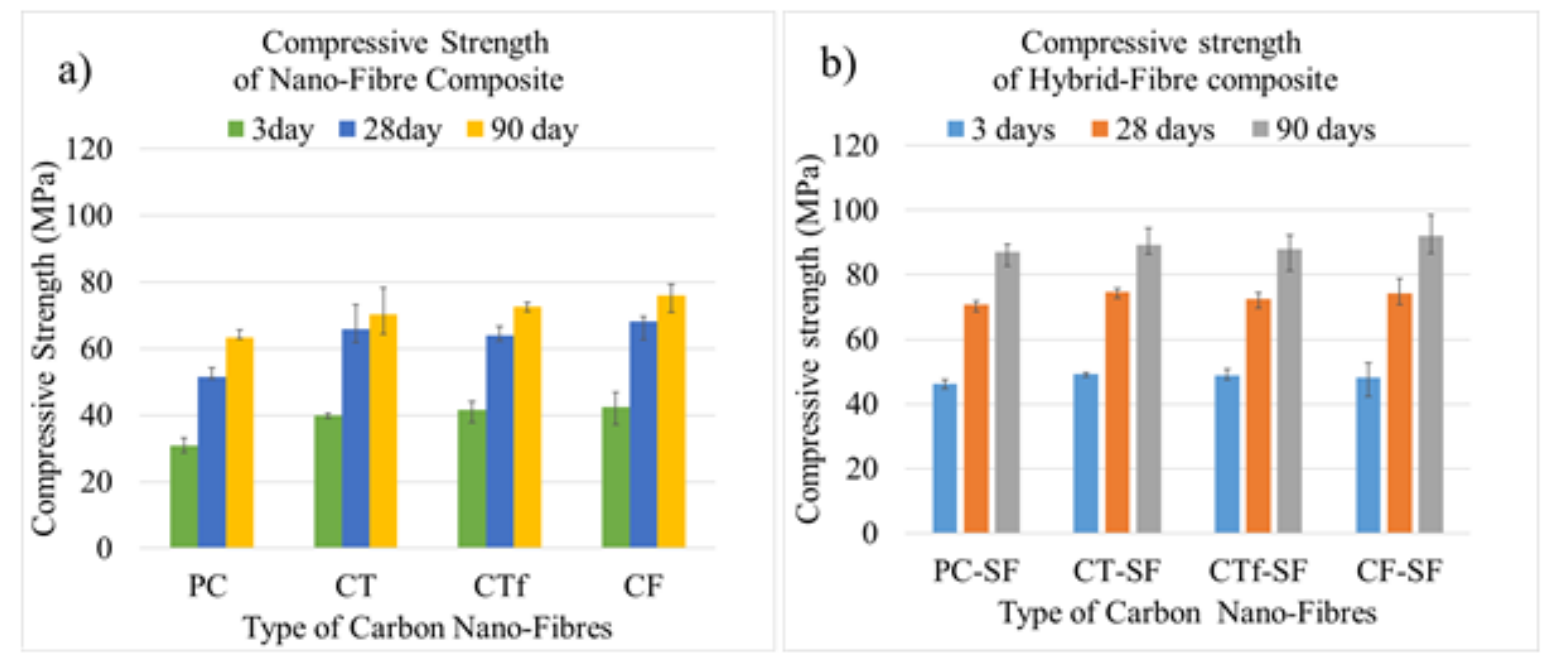

Fig. 4 Compressive strength after various ages for a) nano-fibre composite specimens containing MWCNTs (CT), F-MWCNTs (CTf), and CNFs (CF) in addition to control specimens (PC) and, b) Hybrid fibre composites containing MWCNTs (CT-SF), FMWCNTs (CTf-SF), and CNFs (CF-SF) in addition to control specimens (PC-SF). 

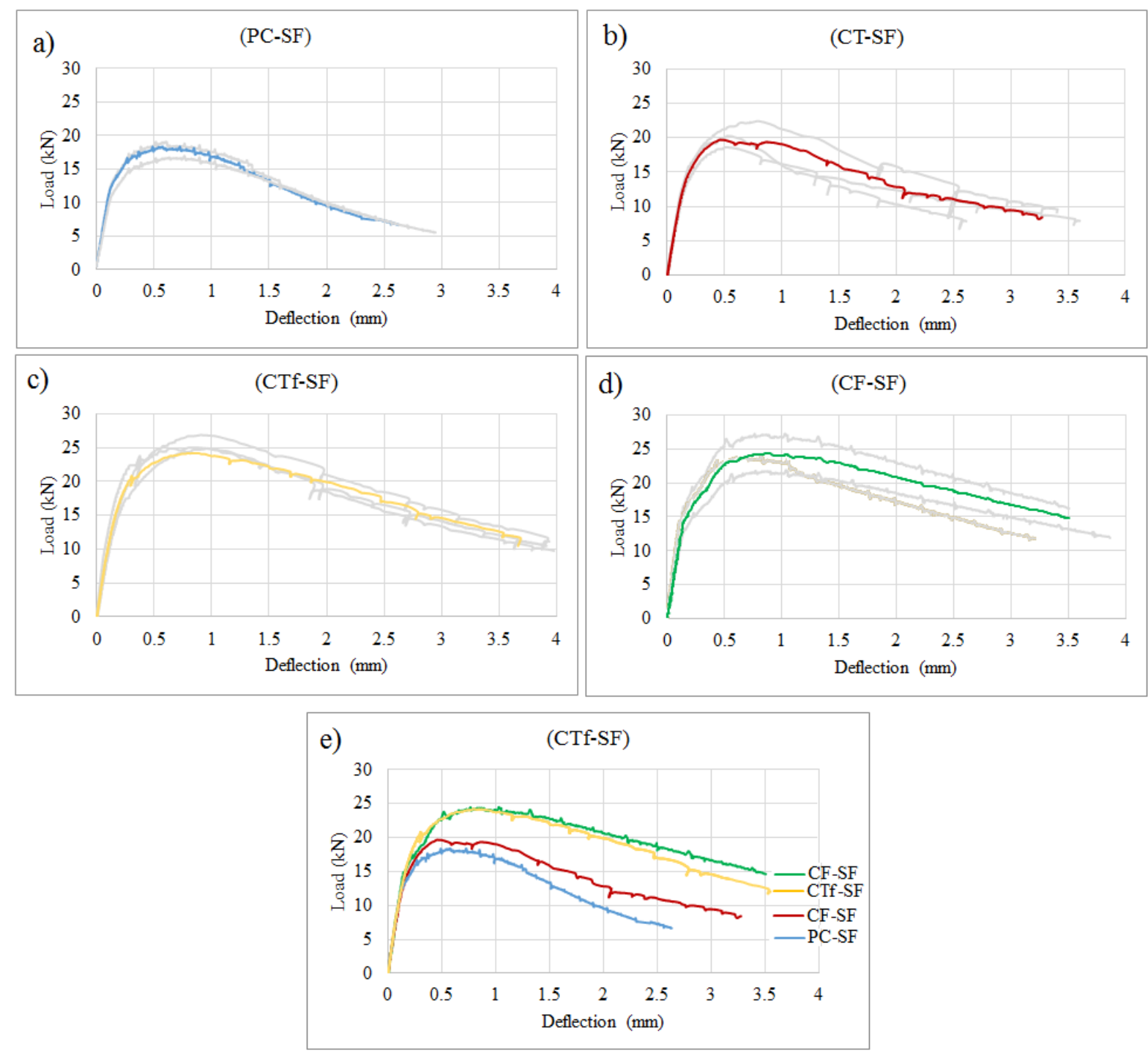

Fig. 5 Load-displacement curves for Hybrid Fibre Composites in four-point bending tests, which represent the effect of nano fibre type on the composites after 3 days, a) control mix PC-SF, b) carbon nanotubes CT-SF, c) functionalised carbon nanotubes CTf-SF, d) carbon nanofibres CF-SF. Graph e) shows curves fitted onto one graph, to allow comparison between different nanofiber types. 

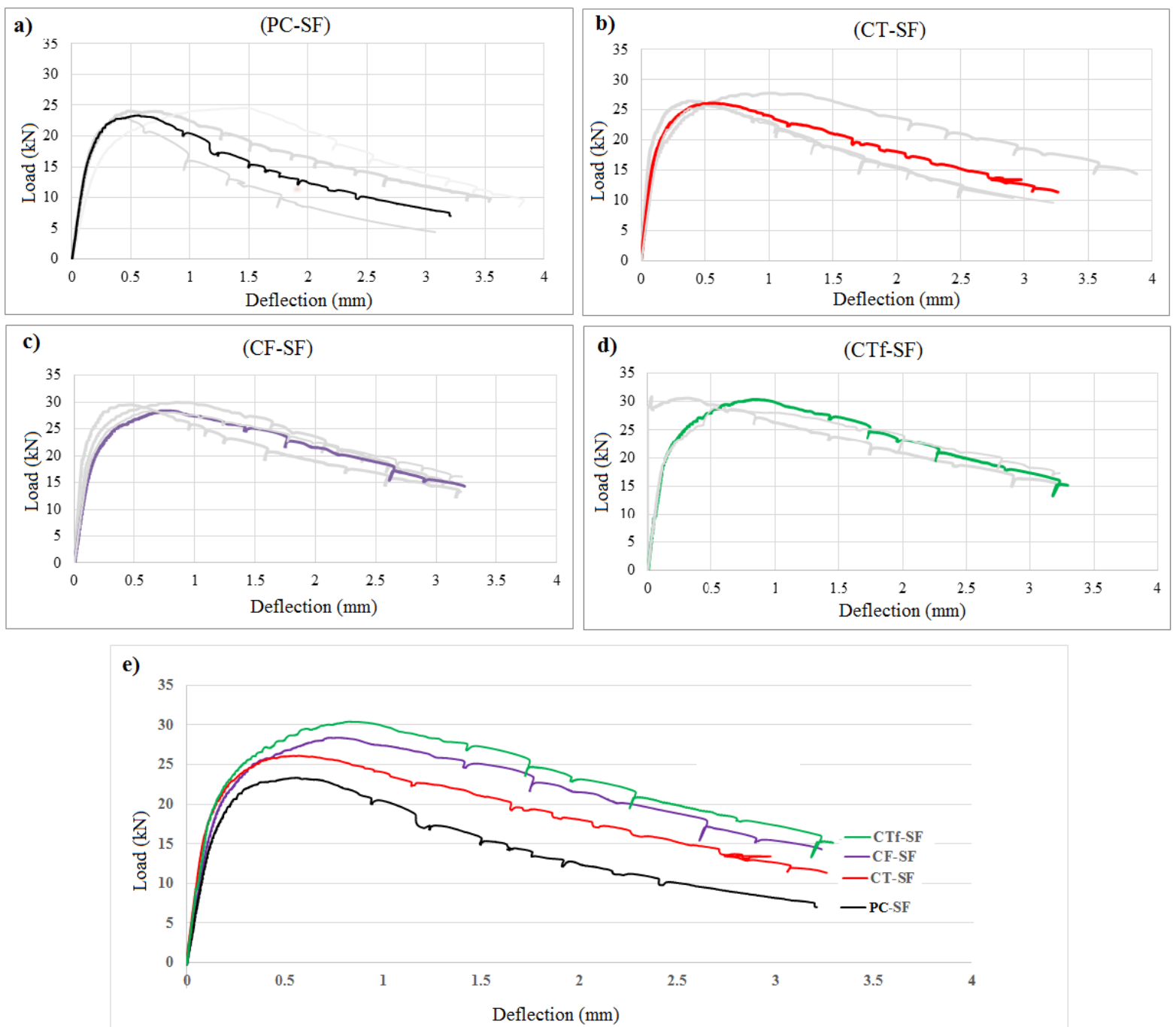

Fig. 6 Load-displacement curves for Hybrid Fibre Composites in four-point bending tests, which represent the effect of nano fibre type on steel-fibre containing composites after 28 days, a) control mix PC-SF, b) carbon nanotubes CT-SF, c) carbon nanofibres CF-SF, and d) functionalised carbon nanotubes CTf-SF. Graph e) shows curves fitted onto one graph, to allow comparison between different nanofiber types. 


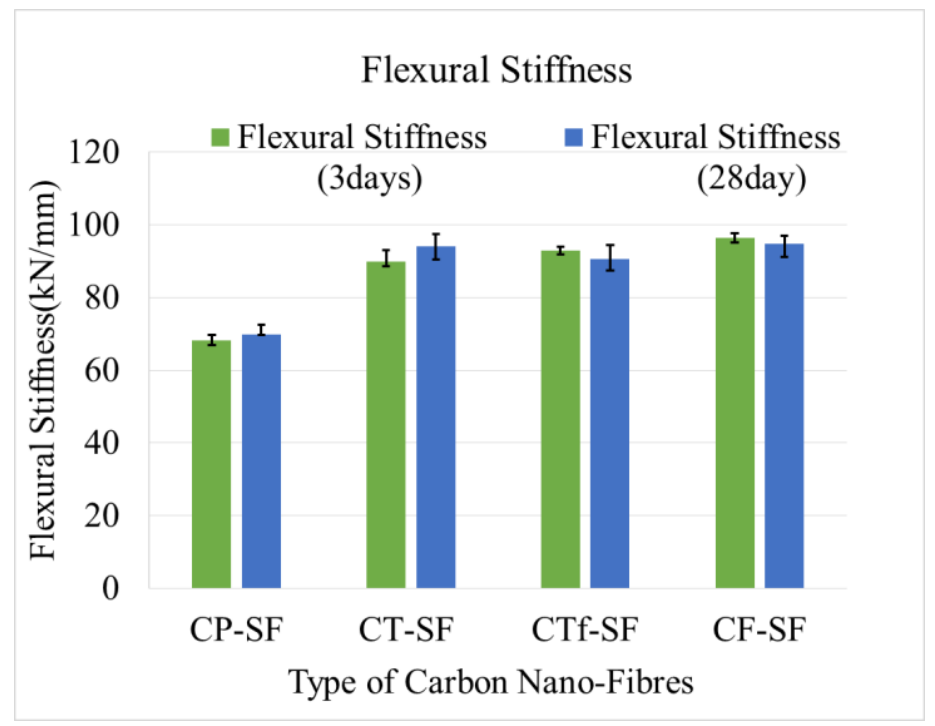

Fig. 7 Flexural Stiffness of Hybrid-Fibre composites containing different types of nano-fibre; MWCNTs, F- MWCNTs, and CNFs, after 3 days and after 28 days.
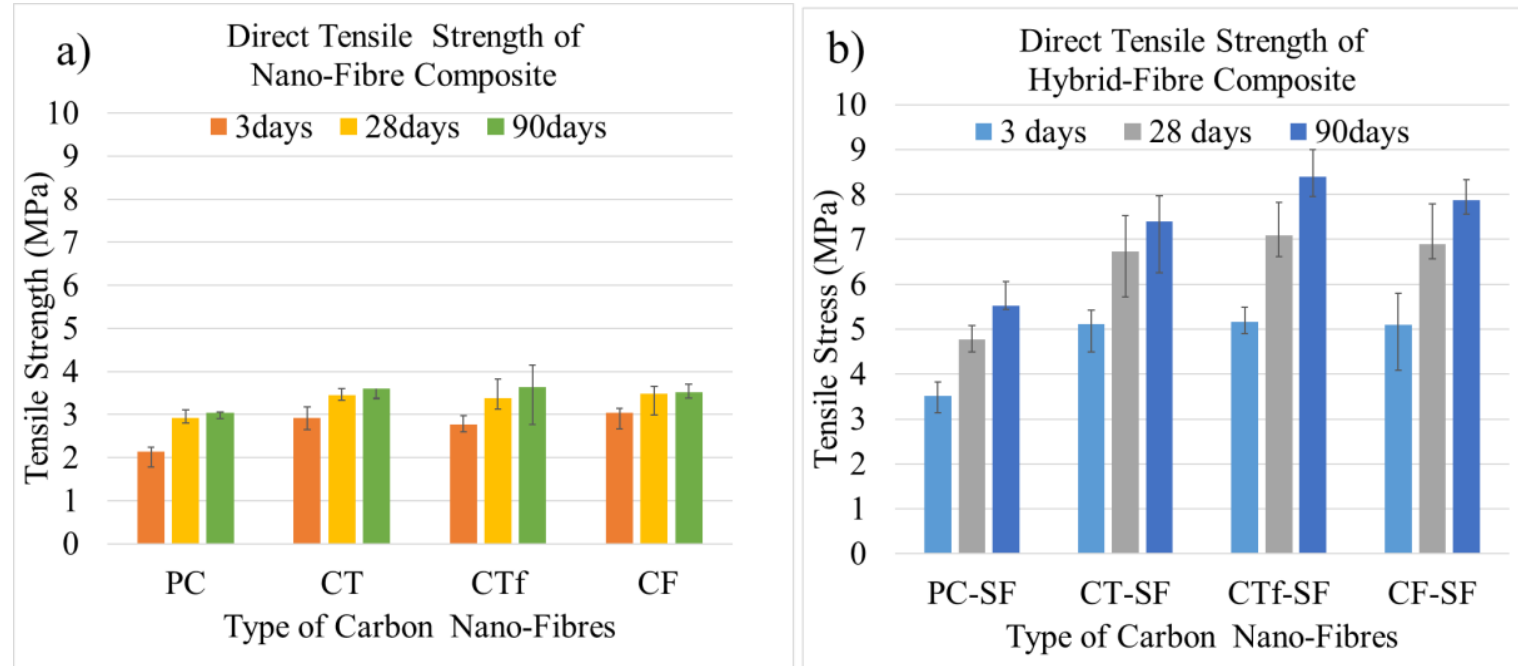

Fig. 8 Direct tensile strengths, after various curing ages, of a) nano-fibre composite specimens containing MWCNTs, F-MWCNTs, and CNFs in addition to control specimens (only cement mortar) and, b) Hybrid-Fibre composites containing MWCNTs, F-MWCNTs, and CNFs in addition to control specimens. 

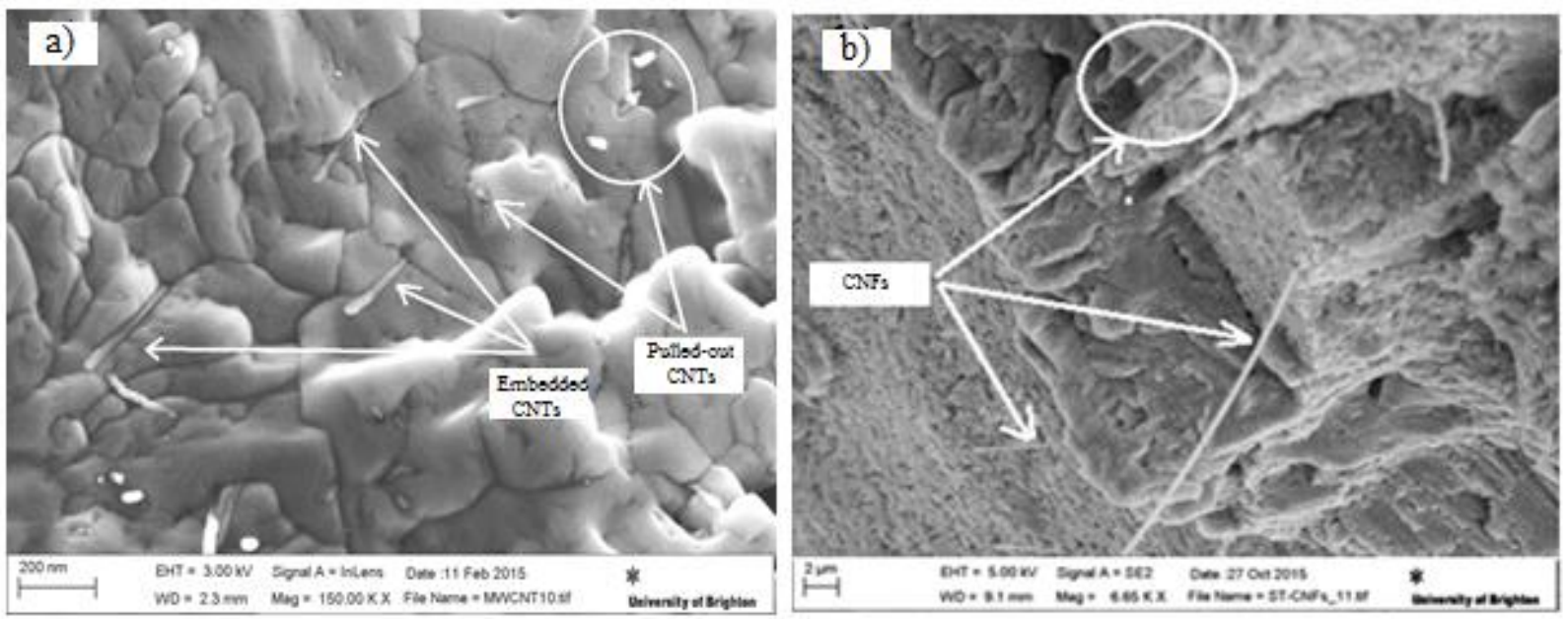

Fig. 9 High magnification SEM images of specimens before tensile testing containing a) carbon nanotubes and b) carbon nanofibres
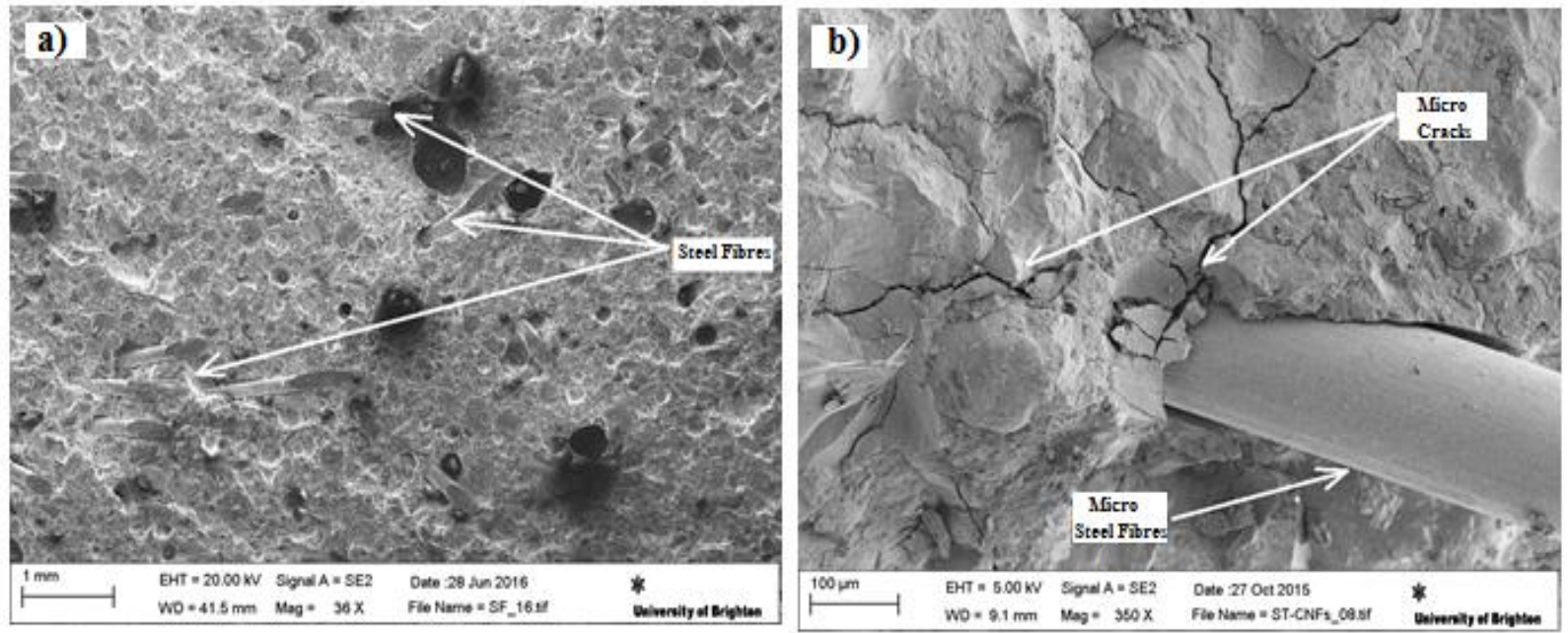

Fig.10 Low magnification SEM images of steel fibre containing (hybrid) composites showing a) fibre dispersion, and b) micro-crack propagation within the cement matrix 

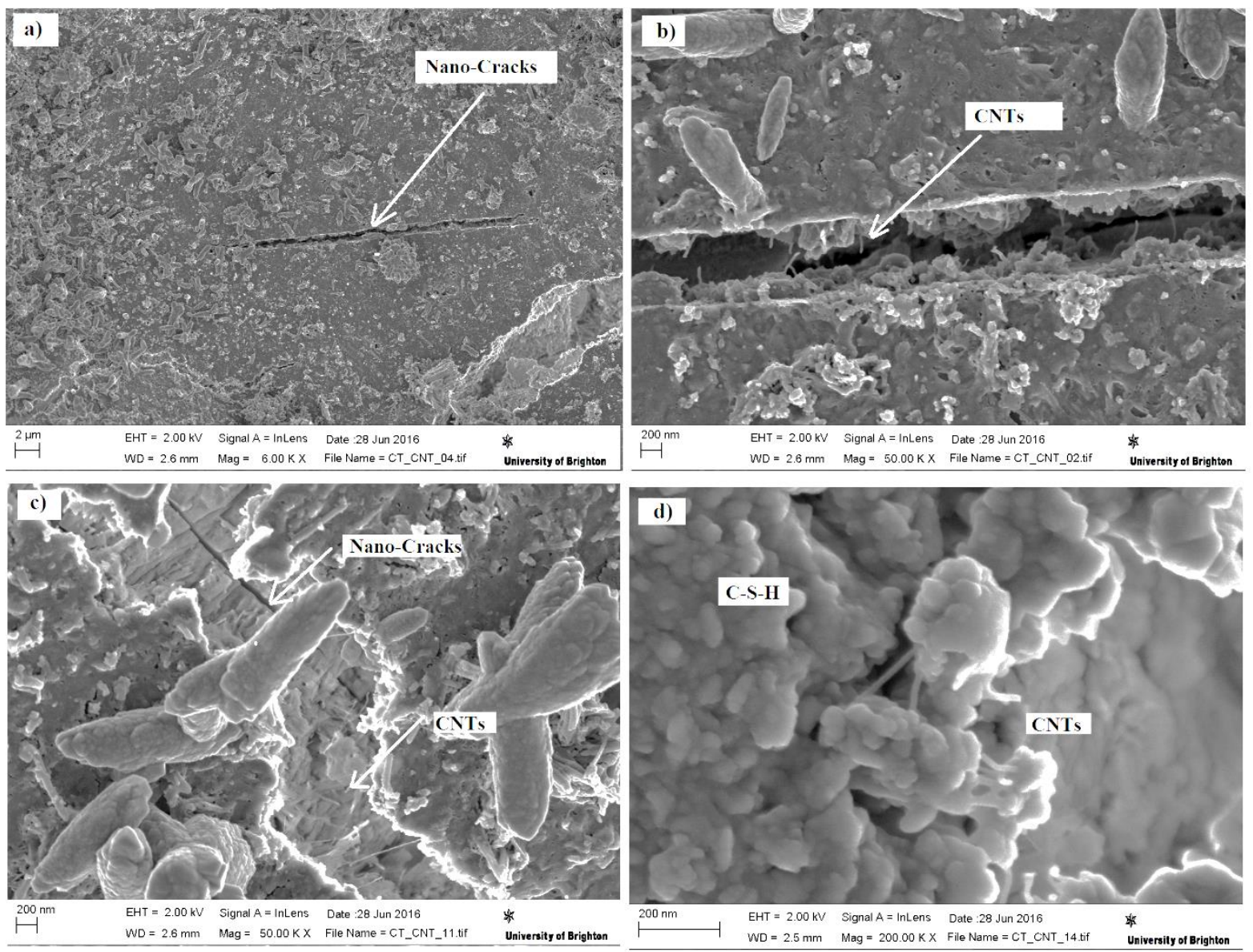

Fig. 11 SEM images at different magnifications of cementitious composites containing CNTs; a) low-magnification image depicting the presence of a nanocrack, b) highmagnification image showing pulled-out and ruptured nanotubes along the microcracks, c) shows the multiple scale of crack propagation, and d) shows nanotubes arresting the cement hydration products. 

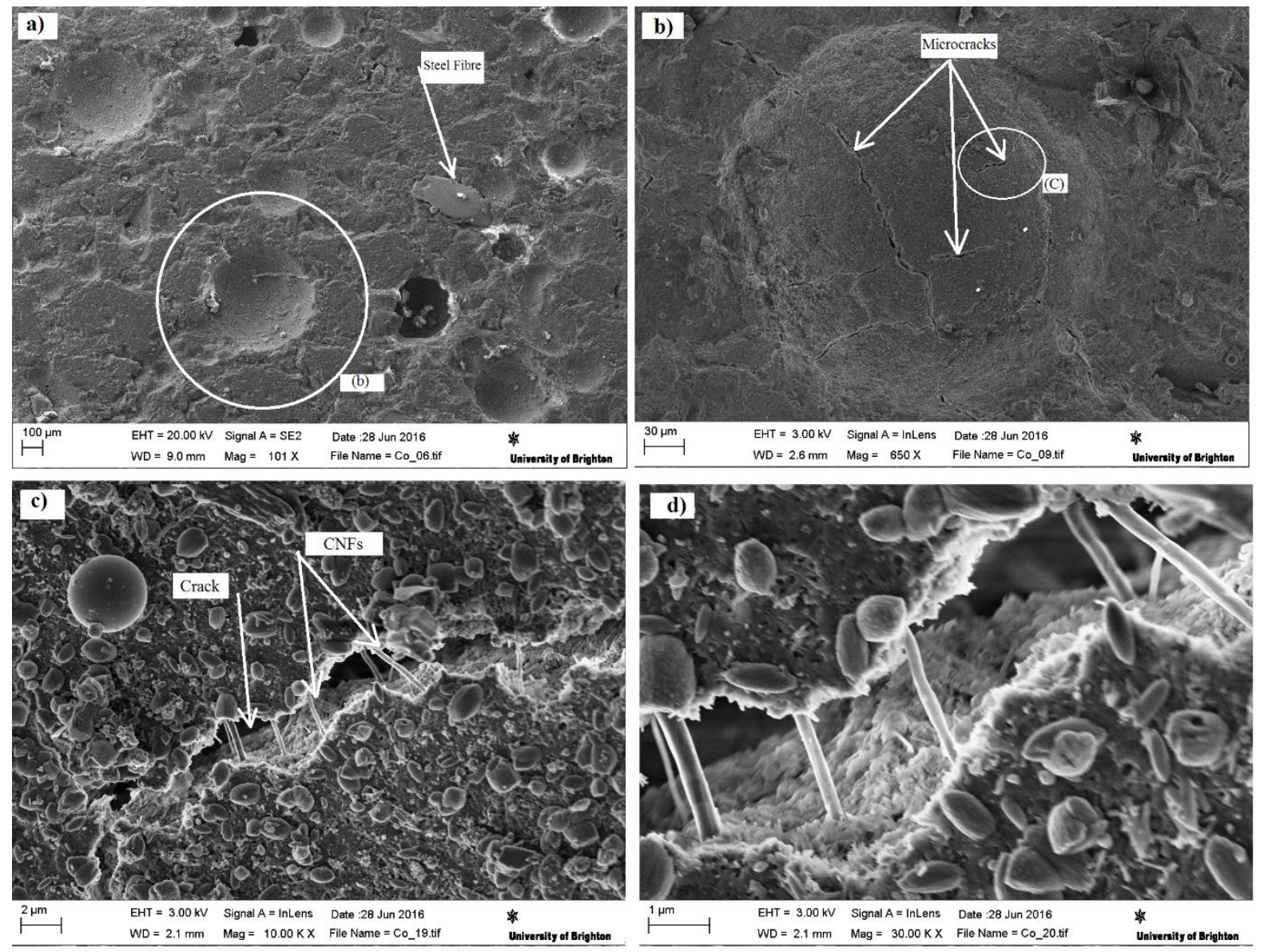

Fig. 12 SEM images at different magnifications of cementitious composites containing CNTs; a) and b) are low-magnification images depicting the presence of microcracks, c) and d) relatively high-magnification images showing nanofibres bridging across the microcracks. 


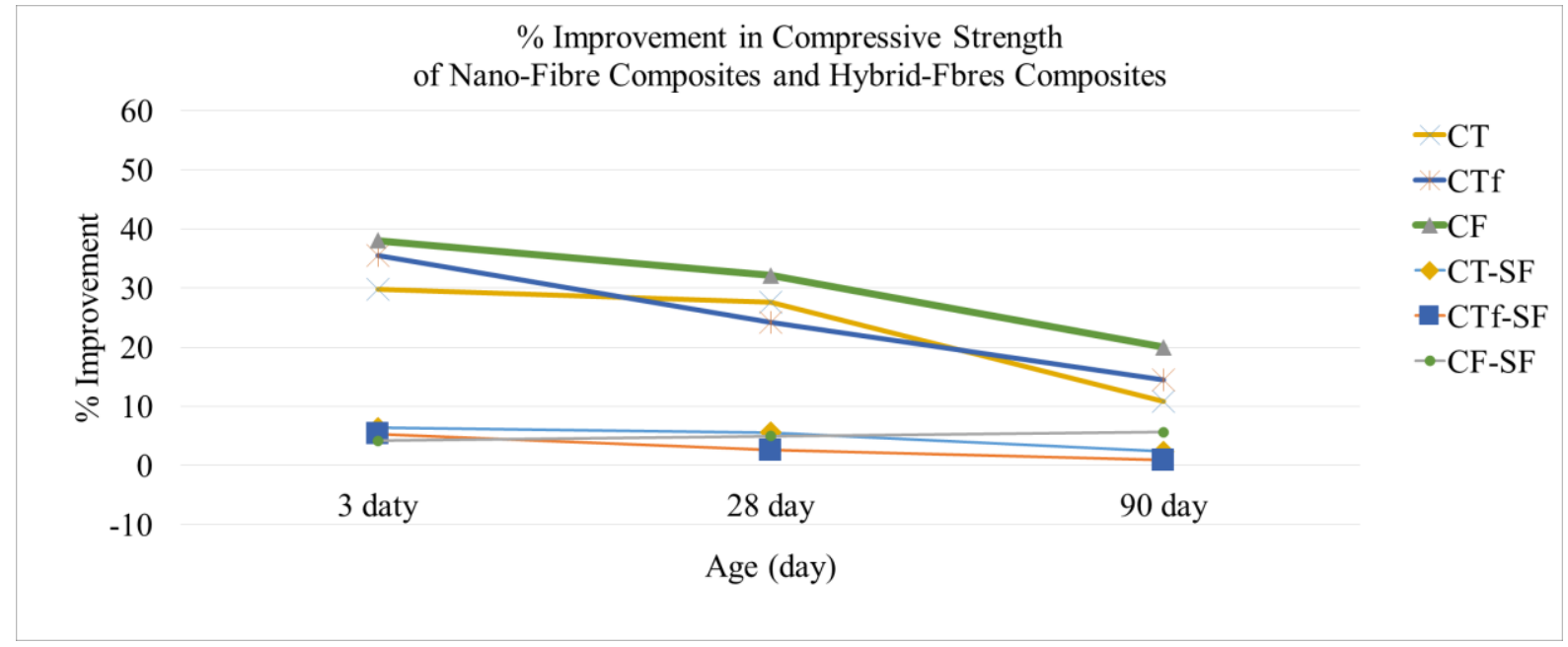

Fig.13 Compressive Strength Improvement (\%) relative to control specimens for Nano-Fibre Composites, and Hybrid Fibre Composites

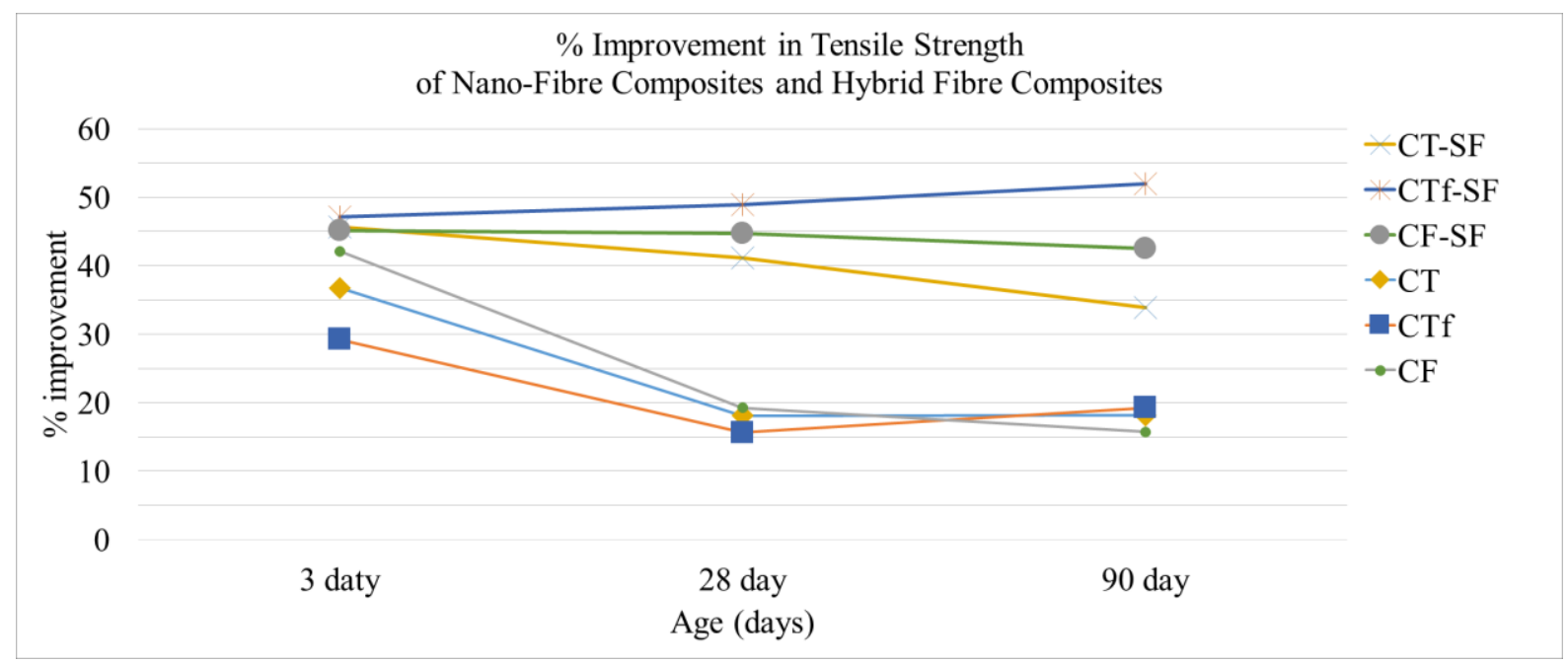

Fig.14 Tensile Strength Improvement (\%) relative to control specimens for Nano-Fibre Composites, and Hybrid Fibre Composites. 

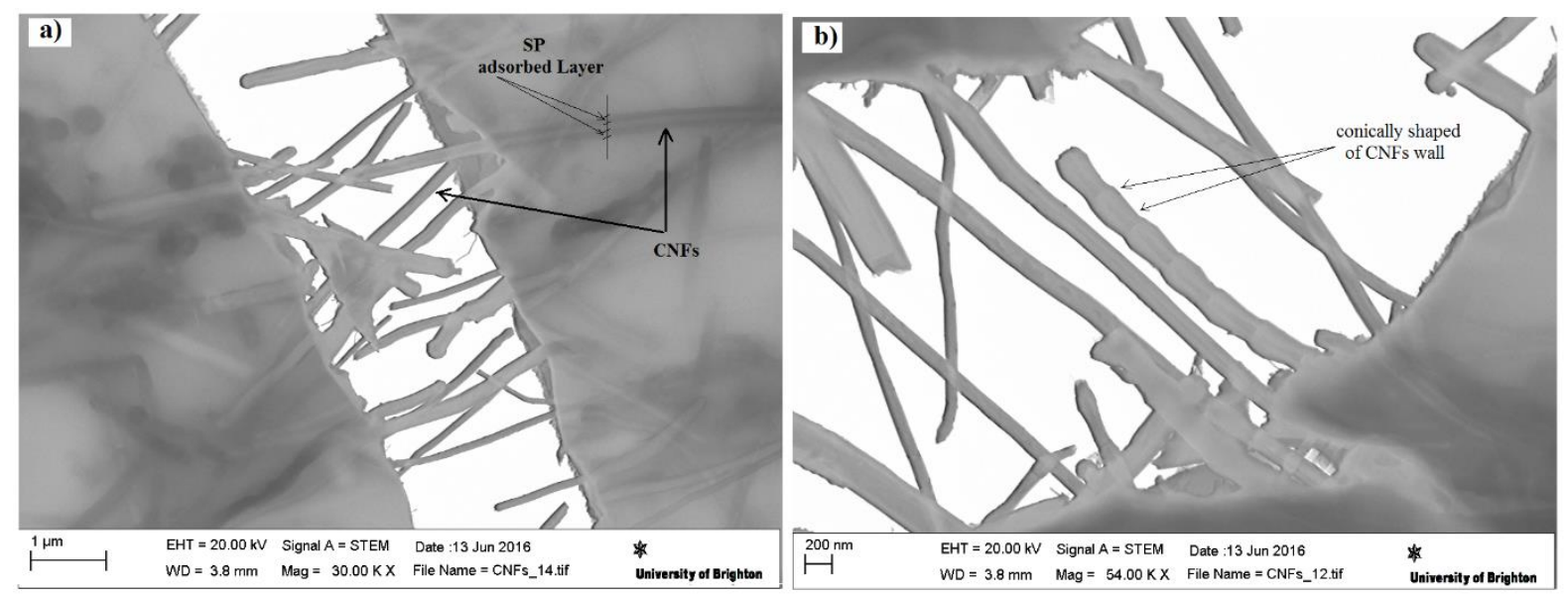

Fig. 15 TEM high magnification images showing the morphology of carbon nanofibers. a) shows an adsorbed layer of SP on the surfaces of the nanofibres, b) shows the outer surface of CNFs, which consist of conically shaped graphite plates angled with respect to the longitudinal fibre axis 